\title{
Contemporary diagnostic methods for ship engines: a report on scientific research activity of Polish Naval Academy in this field
}

\author{
Zbigniew Korczewski, Ph. D. \\ Polish Naval Academy
}

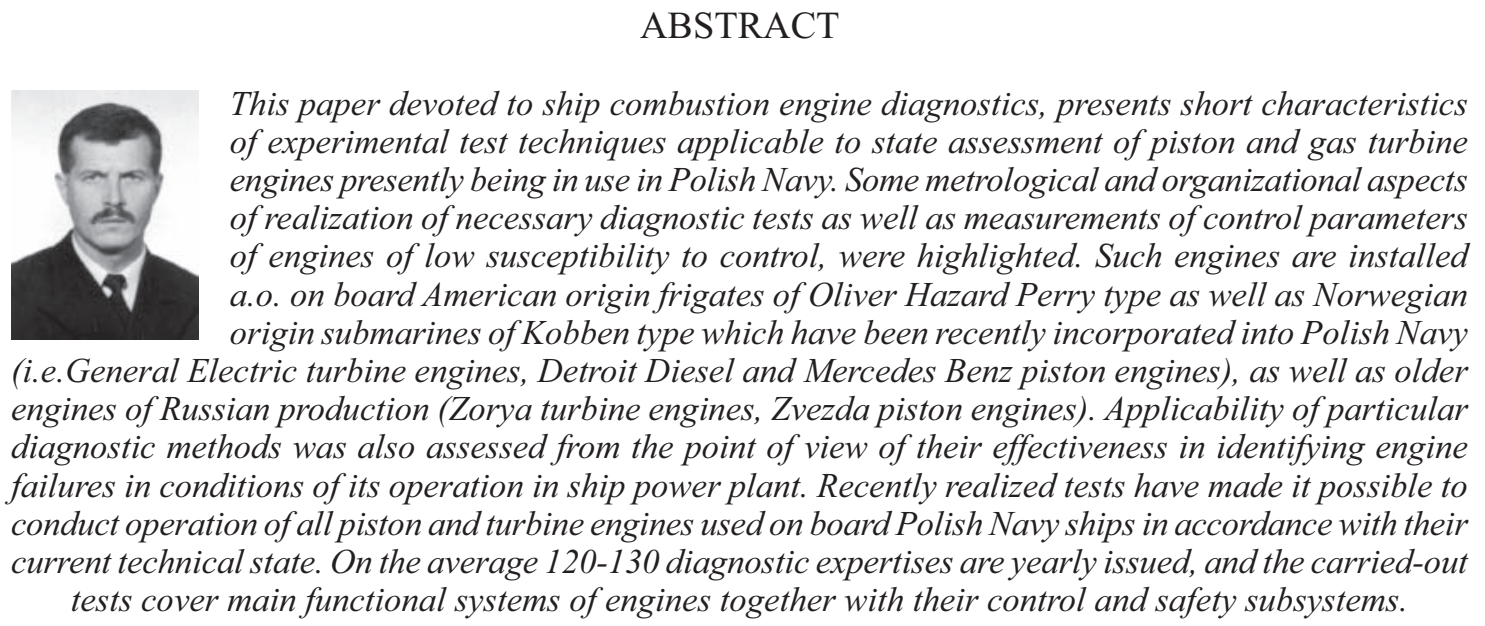

Keywords: marine diesel and gas turbine engines, technical diagnostics, base diagnostic system, operational examinations

\section{INTRODUCTION}

Main research activity of the Institute of Ship Construction and Operation (IKiEO), Polish Naval Academy (AMW), is focused on the problems of diagnostics of ship combustion engines (both of piston and turbine kind). The activity has been developed continuously since 1982 owing to efforts of the following research teams: that dealing with turbine engines and supervised by Prof. Charchalis, A., that dealing with piston engines under supervision of Prof. Piaseczny,L., and Dr Polanowski, S., as well as that dealing with diagnostics of flow systems of turbine and piston engines under supervision of this author.

Introduction to Polish Navy, in recent years, driving engines of a new type of low susceptibility to control, makes it necessary to search for new, alternative diagnostic methods providing possibility of carrying out a complex assessment of technical state of the engines independently from very expensive servicing.

In this paper is described the range of scientific research undertaken in the Institute, which have been traditionally focused on the area of operation of ship machines and devices, including a.o. development of assessment methods of technical state of ship engines (and not only) being in service conditions on board a ship. Also, selected scientific problems dealing with diagnostics of ship piston and turbine combustion engines, being recently under research in the Institute, are presented.

The below presented illustrative material was divided in two independent parts: the first-devoted to diagnostics of piston engines, the second- to diagnostics of turbine engines. The described "cuisine" of diagnostic techniques contains selected methods of diagnostic activity based on the following scope of measurements of:

* Gasodynamic parameters of working medium, of high- and low variability,

* Vibrations and their spectral and correlation analysis,

* Metallic contamination in lubricating oil,

* Torque,

* Emission of toxic compounds contained in exhaust gases,

* Parameters of supplied fuel,

* As well as endoscoping examinations.

It should be added that a part of diagnostic instruments can be sucessfully applied to assessment of technical state both piston and turbine engines, e.g. an endoscopic set or gas analyzers. However procedures for realization of diagnostic tests are different as they are adjusted to a given type of engine, from case to case. A strategic aim of the presented diagnostic methods, continuously developed and modernized, is to bring them to practice of operation of ship engines installed on Polish 
Navy ships and subjected to diagnostic survey in accordance with their current technical state.

\section{DIAGNOSTICS OF PISTON ENGINES - A HISTORICAL OUTLINE}

Since 1982 in the Institute a series of scientific research investigations concerning the diagnosing of piston combustion engines has been realized. The undertaken scope of work has inspired actions leading to elaboration of effective and complex diagnostic methods applicable in service conditions of ship engine. A strategic aim was to pass to engine operation process in accordance with its technical state. As a result the " Basic diagnostic system" was implemented into the operational system of Polish Navy ships. Its concept and realization resulted from:

凊 the task project no. 148-39/C-SO/93.: „Basic system for diagnosing and predicting the technical state of piston combustion engines",

凊 the research project no. 9T12D00211.: „A method of diagnosing the main design systems of piston engines and compressors with application of analysis of vibration envelopes in the domain of crankshaft rotation angle", realized by the team under supervision of Dr Polanowski. (Fig. 1).

Since 1992 have been systematically carried out diagnostic tests of piston engines of every type appplied to propelling Polish Navy ships. Periodic assessment of technical state of the engines is realized by an experienced research team specialized in application of the newest methods of diagnosing in difficult conditions of ship operation. Realization of such tests is based on successive indication of engine cylinders during its steady operation under load within representative ranges.
With the use of special analyzers of fast-varying quantities [20] is carried out comparative, statistical and subject-matter analyses of developed indicator diagrams, runs of vibration accelerations generated by working mechanisms connected with cylinder system and transmitted to a measurement point on engine head, as well as runs of other quantities characterizing working processes in engine cylinders, recorded in the domain of crankshaft rotation angle. The so determined diagnostic measures: mean indicated pressure, indicated power, maximum combustion pressure and rate of cylinder pressure increase $d p /$ $d \alpha$ etc provide important information on overall technical state of constructional elements of combustion chamber. Results of the tests are used for analyzing trends, assessing changes in technical state of engines and preparing an operational decision.

The presently performed investigations make it possible to carry out, in accordance with the technical- state control procedure, operation of about 100 engines installed on board Polish Navy ships. On average, 75-80 expertises on technical state of the engines are yearly issued $[21,23]$. And, only those engines are subjected to the diagnostic control system which are fitted with indicator valves.

\section{ENDOSCOPIC DIAGNOSTICS}

Novel ship engines are fitted with more and more perfect control - measurement systems to measure parameters characterizing their loading state. Despite that, from service practice are known cases of severe failures of engines, whose primary causes have not been found in a proper time, e.g. failures due to excessive vibration resulting from loss of stability of mechanical system and - in consequence - occurence of a resonance.
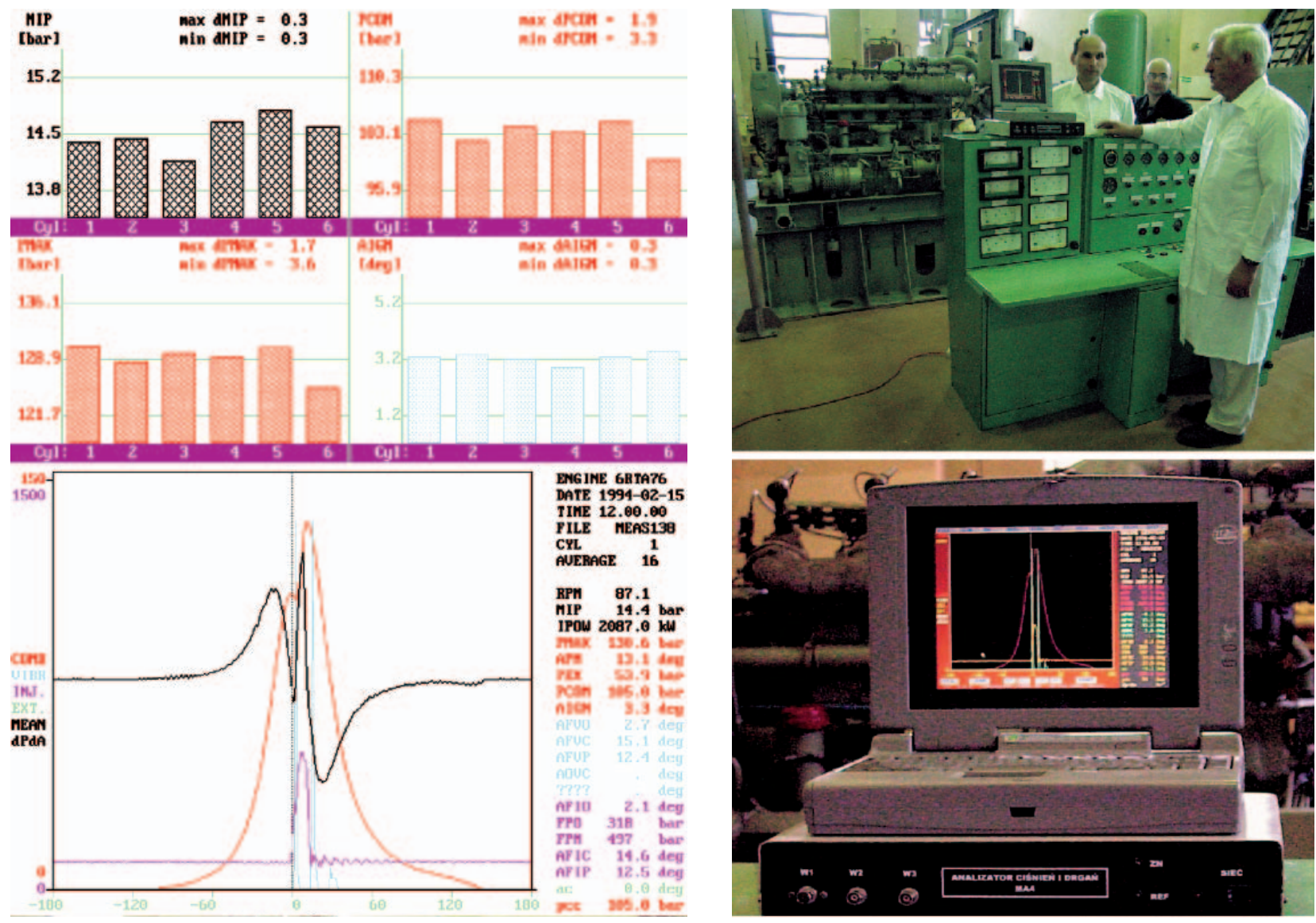

Fig. 1. The diagnostic team of Dr Polanowski at the stand for testing the cylinder systems of Henschel engines - cylinder pressure analyzer example results of testing the engine combustion chamber 
Difficulties in recognizing failures of ship combustion engines on the basis of thermal-gas-dynamic parameters characterizing working processes, are associated with proper interpretation of symptoms of a given failure. The symptoms are often identified as those arising from natural ageing process, contamination or wear of engine elements, determined by duration time of engine operation. In such cases external symptoms are usually concurrent and difficult for unambiguous determination. A special case forms the problem of analysis of diagnostic parameters for assessment of technical state (tightness) of the PRC system (Piston-Ring-Cylinder) of ship multi-cylinder piston engine deprived from possible application of cylinder indication. It often happens that trend curve of exhaust gas temperature changes only slightly deflects whereas piston head becomes burned through due to an injector failure. In such cases the only possibility to obtain any diagnosis of technical state of engine is ensured by visual inspection of its internal spaces with the use of endoscopes (elastic fibrescopes and stiff borescopes). In this non-invasive, very fast, inexpensive and unambiguous way all doubts bothering engine operator can be removed.

To operation process of ship combustion engines new diagnostic test methods are commonly introduced. Endoscopy which has been earlier used mainly for assessing technical state of flow part of turbine engines is dynamically developing and now it serves as a very useful and even indispensable tool for the diagnostic team of the Institute in its activity concerning piston engines especially those being in failure states or in the case of necessary prolongation of time interval between overhauls [23]. The team in question is equipped with the endoscopic set of OLYMPUS and STORZ firms (Fig.2).
The set is composed of three borescopes differring to each other with length of optic part, diameter and observation angle of diagnosed elements, namely: $90 \mathrm{~cm} / 8 \mathrm{~mm} / 90^{\circ}$, $30 \mathrm{~cm} / 4 \mathrm{~mm} / 0^{\circ}, 30 \mathrm{~cm} / 10 \mathrm{~mm} / 120^{\circ}$. The latter one is especially useful in diagnosing combustion chambers and valve seats. The endoscopes show their high usefulness in hard accesible places of engine, e.g. combustion chambers - especially in the case when the disassembling of the head is difficult and time-consuming, in turbocharging system or internal spaces of mechanisms coupled with engine's crankshaft. In Fig. 2. a way of introducing the endoscope tip to internal space of piston engine, is presented. After disassembling the injector the endoscope makes it possible to assess technical state of piston head, cylinder liner surface and other subsystems mounted in it such as: spray nozzles of remaining injectors, inlet and outlet valves, start-up valves etc. The endoscopic inspection method plays special role in diagnosing the multi-block and multi-cylinder engines. For instance, in the engines of radial arrangement, of M503 type (having 42 cylinders) or M520 one (having 56 cylinders), installed in engine room, access to lower monoblocks and lower parts of reduction-reversible gear is very difficult. In the case of necessary overhauls, such engine together with the gear must be coupled out of propeller shaft, then heeled and lifted and sometimes even rotated inside the engine room so as to ensure access to the $1^{\text {st }}$ or $7^{\text {th }}$ cylinder block. From service practice it results that a fibresoscope of a sufficiently long light pipe of optical system makes it possible to avoid such troubles and thus to save realization time of overhauls and their costs even by $25-30 \%$ [23].

Systematic endoscopic tests carried out in the frame of periodical maintenance surveys of ship engines operating in

\section{Set of borescopes}

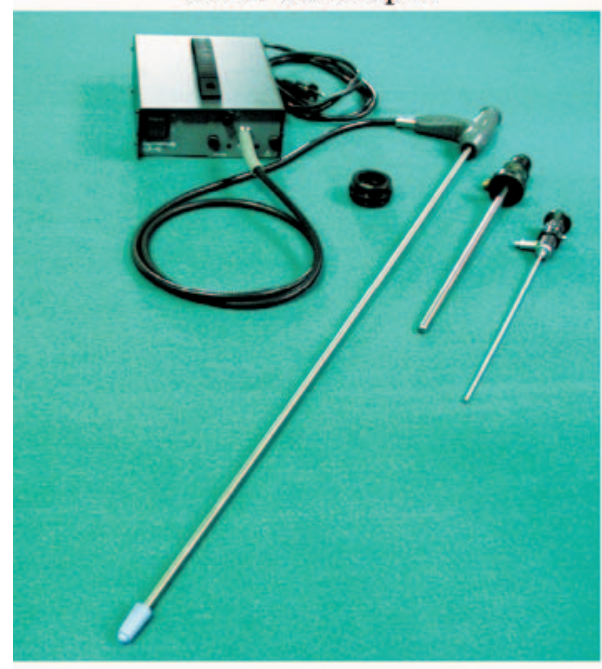

\section{Results of endoscopic examinations}

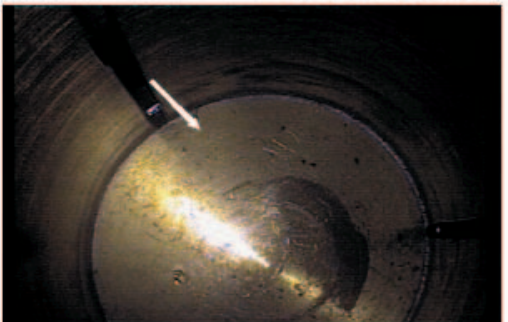

Piston in cylinder liner, mechanical failure of rotor blade

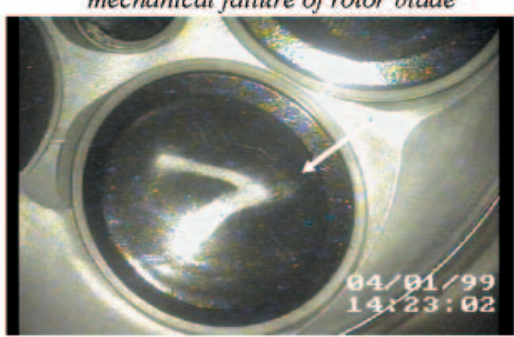

Valves in engine head

Access to inner surface of cylinder liner, piston and valves

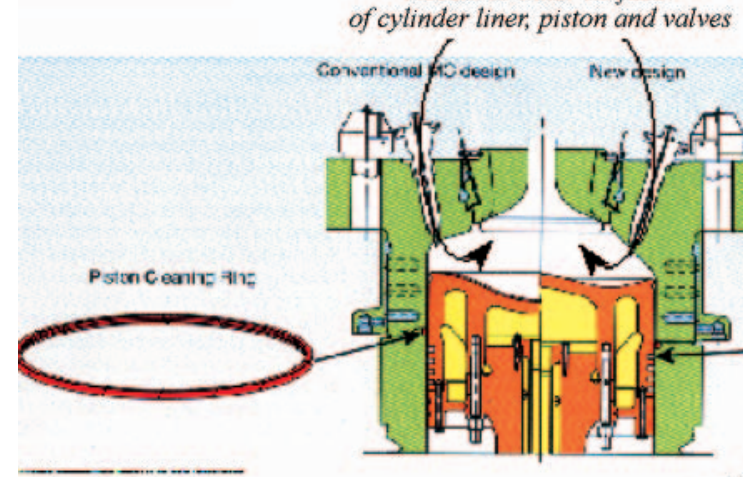

To crankshaft and turbo-charging system

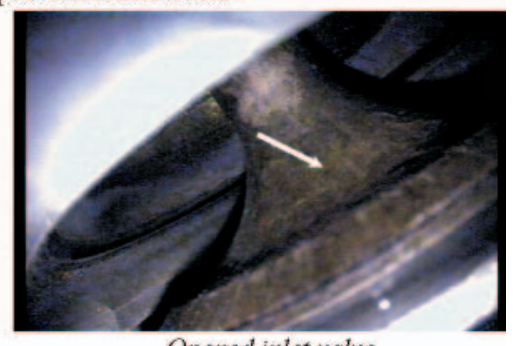

Opened inlet valve

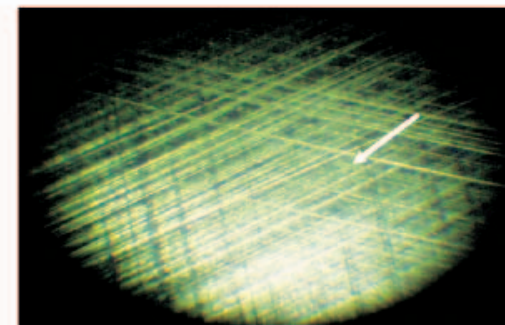

Trace of cylinder liner "honing"

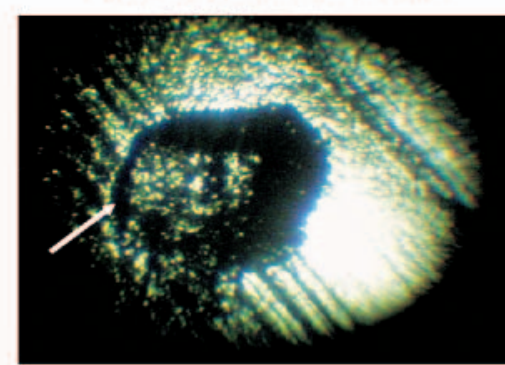

Erosion pit on piston head
Fig. 2. Endoscopic examination of a piston engine - endoscopic set, results of examination of ship engines, access to internal spaces of a cylinder liner 
Polish Navy have confirmed the high effectivenes of the method at relatively easy use of the testing instrumentation. As a result of such overhauls were disclosed many defects which - in the case of their further building-up - could highly endanger engine reliability. Selected defects of ship engines identified during endoscopic tests in service conditions have been systematically published in scientfic journals, a.o. in $[8,14,23]$.

\section{ALTERNATIVE METHODS FOR DIAGNOSING PISTON ENGINES}

The scientific research work carried out in the Institute (under supervision of this author) is aimed at thorough modernization and further development of the so far functioning and proved diagnostic system by adding to it elements for controlling the main functional systems of engine (i.e. the piston-cylinder system, turbocharging system, fuel supply system as well as bearing system) in the situation when to assess technical state of engines not fitted with standard indicator valves becomes necessary. Just such engines (M401, Detroit Diesel and Mercedes Benz engines) are installed a.o. on the Polish Navy base trawlers of F207M type, American-origin frigates of Oliver Hazard Perry type and Norwegian-origin submarines of Kobben type, which have been lately incorporated to Polish Navy.

In the frame of realization of the following research projects:

$\overrightarrow{2}$ „Influence of adjustment of fuel supply system of ship piston combustion engine on spectrum of shaftline torsional vibrations ",

$\vartheta$ „Method of using measurements of cylinder internal pressure during idle operation to assessment of technical state of bearing system of ship piston combustion engine in service conditions",

- „Diagnostic tests of supercharging system in the aspect of changes in combustion process occurring inside engine cylinder",

- „Research on influence of operational factors on performance and efficiency of propulsion systems of Polish Navy ships",

- „Technical state assessment of ship engines of the series of AL, ASV and M520 types on the basis of measurement data collected by main propulsion monitoring systems of the ships of 206FM and 660 type"

was elaborated a number of new diagnostic stands which make it possible to indirectly assess the fuel combustion process in engine cylinders when their indication is not possible.

\section{DIAGNOSTICS OF TURBOCHARGING SYSTEMS}

Turbocompressor constitutes a sensitive and - according to statistics - very unreliable element of four-stroke engine fitted with pulsatory supercharging system. Such situation results from specific operation conditions of ship engines, which are characterized by work at low and variable loads. It leads to an incomplete, and not quite thorough, fuel combustion in cylinders and further gas-dynamical and mechanical consequences of the phenomenon in the form of erosion, decreasing performance and lowering efficiency of turbocompressor, loss of stability of mechanical system, and at last to vibrations which generate accelerated wear of bearings and fatigue cracks of rotor's blades.

In diagnostic tests of pulsatory supercharging systems of ship engines it becomes necessary to identify run of changeability of being -at- disposal energy of pressure pulses of exhaust gases delivered to turbocompressor during one working cycle. On the basis of measurements of instantaneous values of the ram pressure $\mathrm{p} 1{ }^{*}$ and instantaneous values of the static pressure p1, p2, recorded at two control cuts, 1 and 2, of exhaust gas outlet channel, located at the distance L to each other - Fig.3, one determines the peak amplitude propagation velocity of exhaust gas pressure waves generated after opening successive outlet valves of engine cylinders. During next phase of the diagnostic reasoning, harmonic analysis of amplitude spectrum of exhaust gas pressure pulses in turbocompressor supply channel, is performed by means of the fast Fourier transform method $[9,10,11]$.

For instance, from numerical data given in the form of time - frequency characteristics it can be observed which consequences result from elimination of one cylinder from operation: drop of the propagation velocity of exhaust gas pressure waves in turbocompressor supply channel as well as the unwanted concentration of amplitude spectrum of exhaust gas pressure pulses in the channel. In the amplitude spectrum, the fundamental frequency amplitude dominates that speaks about a significant unbalance of gas forces in engine cylinders, which makes destructive action on engine construction of unbalanced inertia forces generated by rotating and to-and-fro moving masses, increasing. The defined diagnostic measure in the form of the ratio of fundamental frequency amplitude and $3^{\text {rd }}$ harmonic amplitude in vibration spectrum, for which trend analysis of changes of values is carried out during process of operation, makes it possible to assess technical state of elements of the PRC system, as well as of turbocharging system of the engine not fitted with standard indicator valves [11].

\section{DIAGNOSTICS OF FUEL SUPPLY SYSTEMS OF ENGINE}

In the frame of the research project: ,Influence of adjustment of fuel supply system of ship piston combustion engine on spectrum of shaftline torsional vibrations " an original technical design was elaborated of a test stand for energy - orientated investigations of ship engines, for which an universal recorder of ship propulsion system performance and efficiency, based on measurements of fast-varying quantities, was built - Fig. 4 [2, 23]. In present, laboratory tests of the recorder are under way (on Sulzer 6AL20/24 engine), also it is tested in real conditions (on Sulzer 6AL25/30 main engine of H-5 tug). The tests cover simultaneous measuring and recording shaftline torsional vibrations and fuel consumption of both the engines. They are aimed at making assessment of influence of engine technical state changes on shaftline torsional vibration spectrum as well as fuel consumption. The experimental simulation consisted in disturbing the steady-state operation of engine by excluding its one cylinder from work. This way was simulated engine operation in the state of partial technical serviceability.

The recorded runs of ship shaftline torsional vibrations are subjected to spectral analysis with the use of the fast Fourier's transform (FFT) [2]. This way the diagnostic measures are determined for assessing technical state of engine cylinder systems and fuel supply system. An original set of methods for indirect assessing runs of gas-dynamic processes in cylinders, applicable also in diagnosing ship engines (and not only) in the case when direct measuring the pressure inside cylinders (due to lack of indicator valves) is not possible, is now in the final stage of elaboration. The set of the methods is scientifically investigated in the doctor thesis of M.Sc. Burski, St.

The achieved results encourage to continue further experimental tests on influence of regulation of fuel supply system and timing gear as well as changes in design structure 


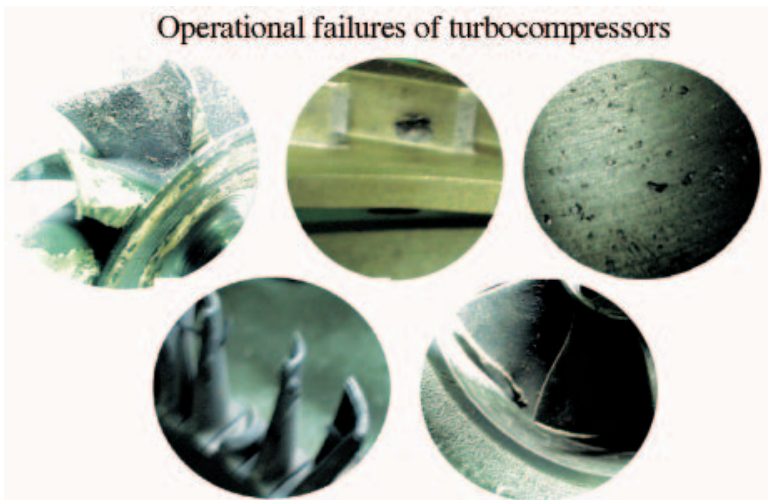

Measurement of instantaneous values of pressure in passage of exhaust gas supplying engine turbocompressor
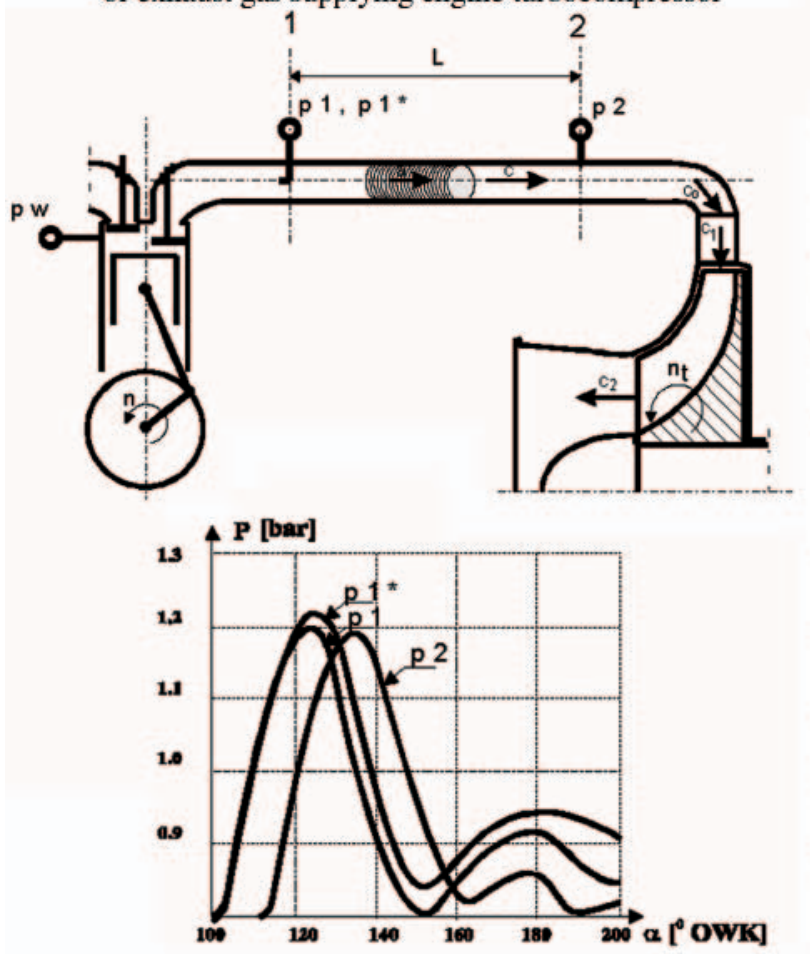

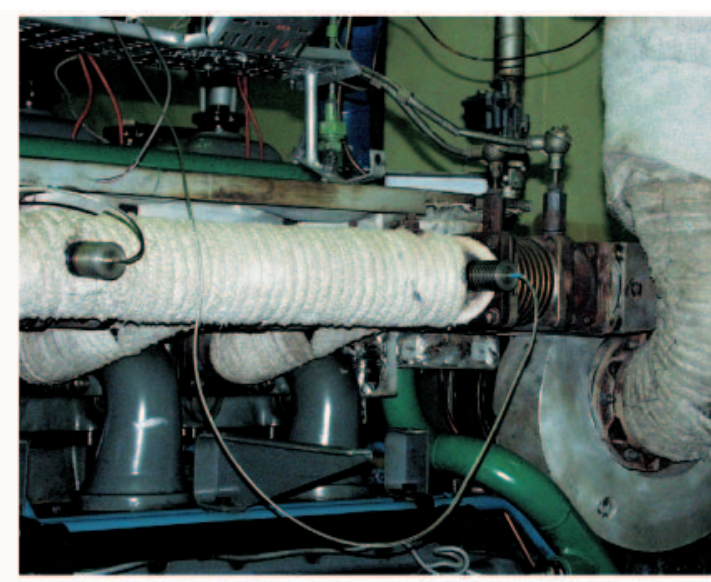

GAS-DYNAMIC ANALYSIS - speed of propagation of exhaust gas pressure wave in passage
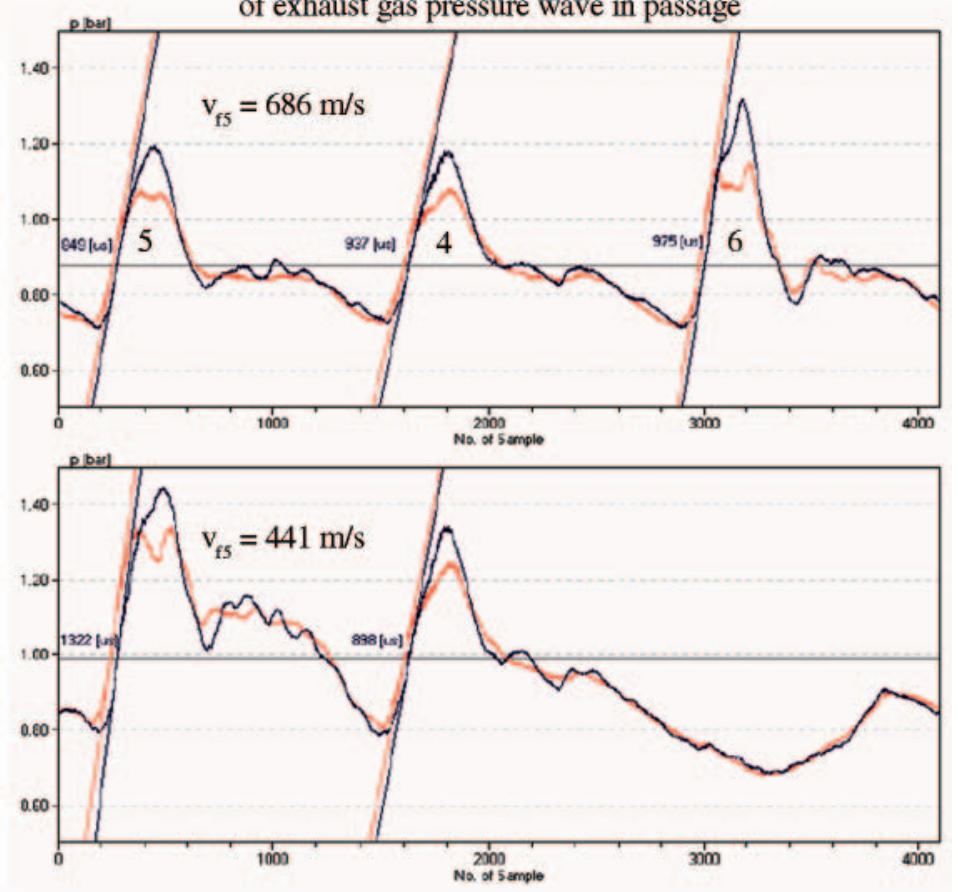

VIBRATION ANALYSIS - ratio of fundamental frequency amplitude and $3^{\text {rd }}$ harmonic amplitude induced by engine operation
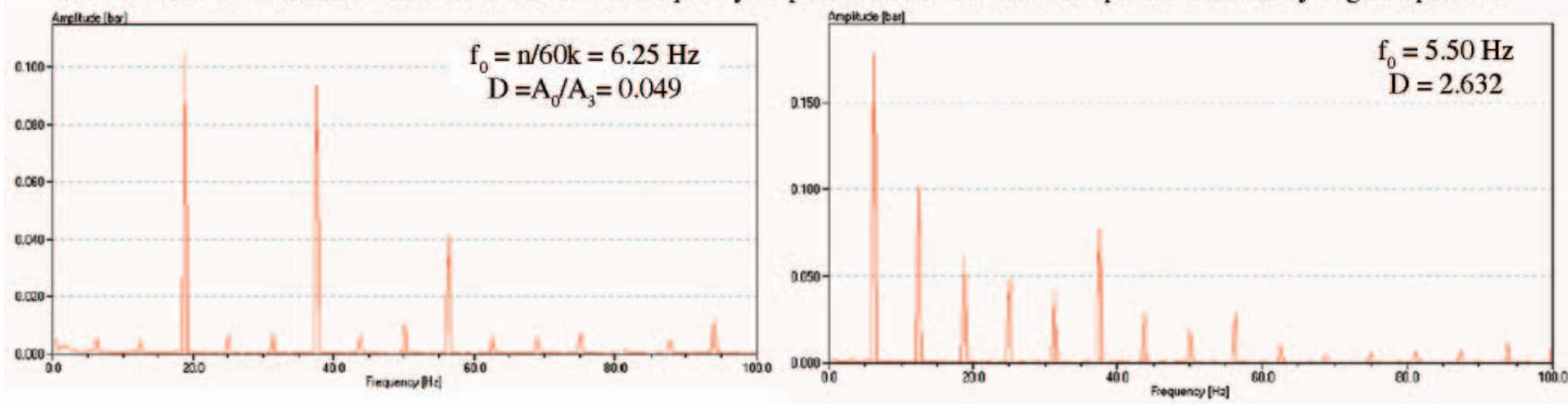

Fig. 3. The stand for the measuring of gas pressure pulses in exhaust gas system - results of diagnostic tests of turbocharging system

of turbine nozzle (i.e. simulation of contamination of blade passages) on the defined diagnostic measures.

\section{DIAGNOSTICS OF BEARING SYSTEMS}

In the Institute is also under way an intensive research on the methods for technical state assessment of engine bearing system, based on the measuring of pressure inside cylinders under idle run. The research is aimed at finding a relationship between technical state changes of bearing system of piston of ship combustion engine (leading to its increased mechanical losses), is based on indication of idle running engine at uncoupled driving unit.

Passive experimental investigations on the problem have been carried out in the frame of the doctor thesis of M.Sc. Wontk, L., since 1997 [23]. In present, in order to verify the proposed set of methods for diagnosing ship engines, active experiments on the laboratory engine where real defects of main and crankshaft bearings have been introduced, are under way. For realization of that phase of the research are used sets of bearing sleeves having wear of different kind and degree, dismounted from real objects out of service - Fig. 5 . 

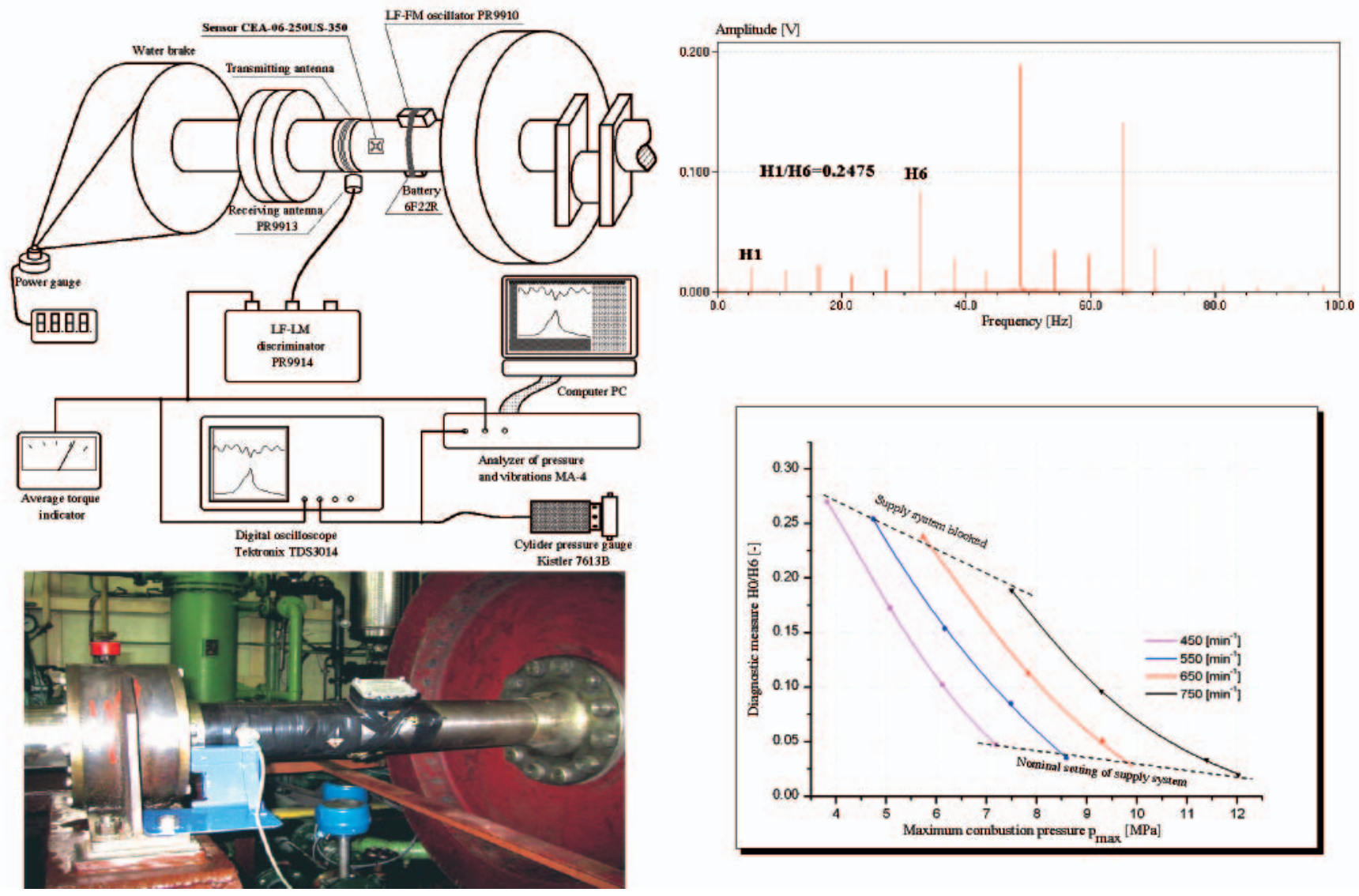

Fig. 4. The stand for measuring torsional vibrations of ship shaftines - results of the indirect testing of runs of processes occurring inside cylinders

As the realized research results indicate, the idle- run indicated power constitutes a sensitive diagnostic parameters of engine. However it does not allow to unambigously localize sources of increased mechanical losses but only to signalize their possible occurence. Hence in order to unambigously determine whether the changeable technical state of bearings is responsible for the increased mechanical losses it is necessary to verify the diagnostic tests by means of spectral tests of metallic particle content in lubricating oil. In present, a programmme of preliminary tests aimed at proper choice of analytical models of copper and lead content is under elaboration.

\section{DIAGNOSTICS OF TURBINE ENGINES - A HISTORICAL OUTLINE}

Since 1986 in the then Institute of Ship Construction and Operation, Polish Naval Academy, several scientific research projects on diagnosing ship gas turbine engines have been realized $[3,23]$. Their scope of themes was inspired by the efforts leading to elaboration of effective diagnostic methods applicable in real service conditions on board a ship. A strategic aim was to pass to the operation process of engines in accordance with their technical state. As a result the "Basic diagnostic system" was implemented into the operational system of Polish Navy ships. Its concept and realization resulted from the following projects:

$>$ The task project no. 148-23/S-SO/93: „Diagnostics of ship gas turbine engines",

$>$ The research projects:

$\Rightarrow$ no. 9 T12D 008 11: „Technical state assessment of ship gas turbine engines on the basis of research on their dynamic features";
$\Rightarrow$ no. 0 T00A 009 16:,, Assessment methods of co-axiality of torque transmission elements of ship propulsion systems";

$\Rightarrow$ no. 0 T00A 062 19: „Elaboration of a diagnostic system for ship gas turbine engines installed on the frigates being incorporated into Polish Navy",

$\Rightarrow$ and also a dozen of tens of R\&D projects and expertises financially supported by the State Committee for Scientific Research and Polish Navy.

The system which is continuously developed and modernized, contains several diagnostic stands which make it possible to perform a complex assessment of ship gas turbine engine (practically of an arbitrary configuration) as well as to elaborate a prediction of its further operation process. The system is equipped with special controlling and measuring instruments as well as analytical tools, which make it possible to perform diagnostic tests of engines during stopovers and sea trials of ships. $[4,12,13]$.

In this chapter are presented short characteristics of experimental test techniques applied to assessment of technical state of General Electric LM-2500 engines and Zoria DR76 and DR77 engines, presently subjected to the diagnostic program in question [24]. Some metrological and organizational aspects of realization of necessary diagnostic tests as well as measurements of control parameters of gast turbine engine in steady states and transient ones (start-up, acceleration and deceleration) are also highlighted. Usefulness of particular diagnostic methods regarding their effectiveness in identifying engine operational unserviceability, has been assessed. In present, investigations are under way to make it possible to carry out engine operation process - in accordance with technical state - of all turbine engines being in use of Polish Navy. Each year, on average 14-16 expertises of engine 

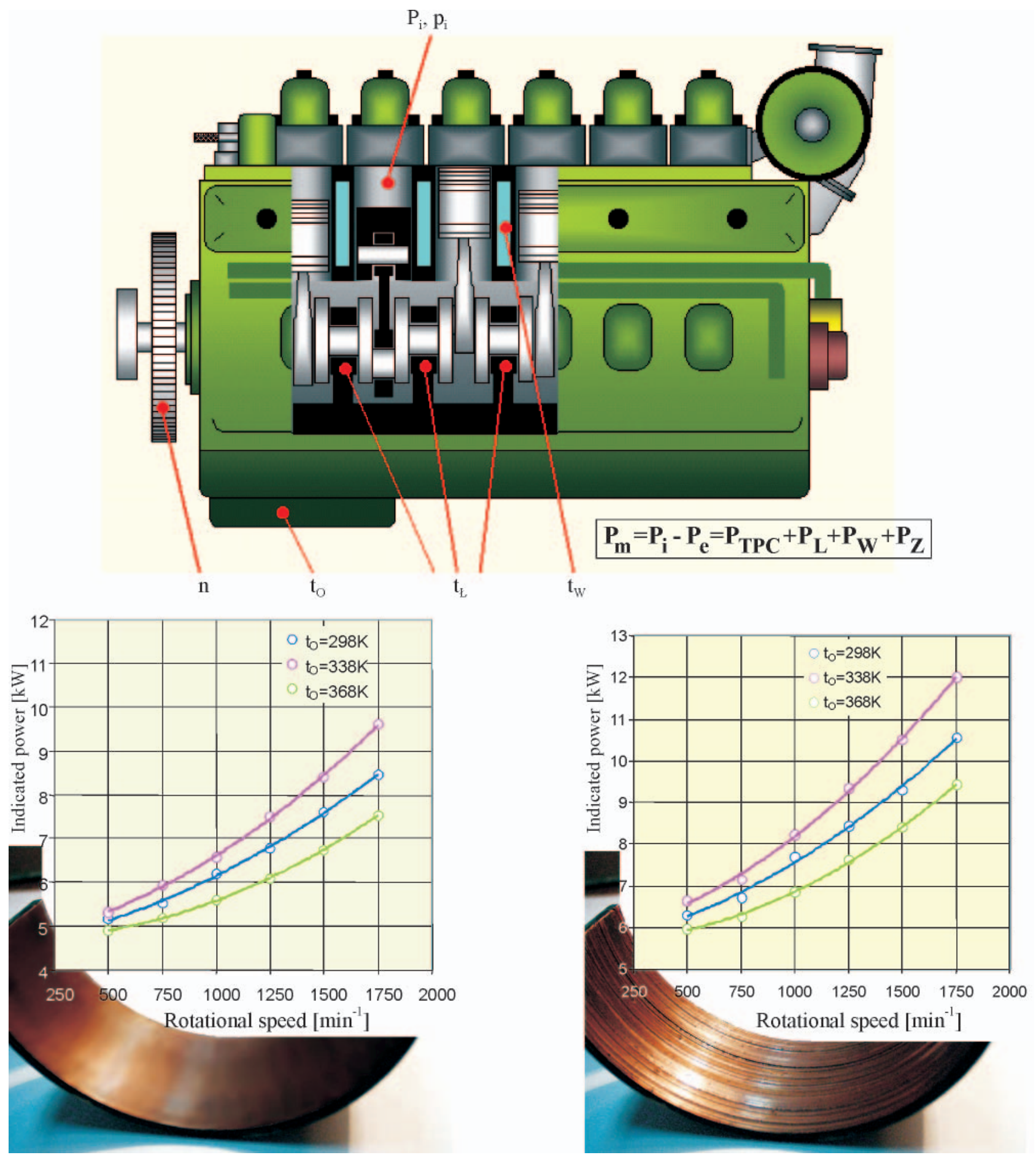

Fig. 5. The stand for the diagnosing of ship engine bearing system - results of tests of bearing sleeves.

Pm-power of mechanical losses of engine, PTPC - friction drag power lost in TPC (piston - piston rings - cylinder) system, $P E$ - friction drag power lost in bearing system, $P W$ - ventilation drag loss power,

$P Z$ - friction drag power lost in mechanisms coupled with cranshaft and timing gear.

technical state are performed, on the basis of diagnostic tests of the main functional systems of the engines together with their control and safety devices [23].

\section{ENDOSCOPIC DIAGNOSTICS OF ENGINE FLOW PART}

For endoscopic examinations of gas turbine engines is used an extended optical set which makes visual inspection and preparation of photographic documentation of internal elements of flow part of engine though inspection openings of abt. $5 \mathrm{~mm}$ in diameter, possible. For carrying out dimensional analysis of internal defects of engine elements, their visualization and documentation in data base a Camedia $\mathrm{C}-2500 \mathrm{~L}$ digital camera of OLYMPUS firm, is used. The camera is connnected with a borescope or fibrescope by means of special links (adapters). Fig. 6. presents the endoscopic diagnostic set used in the basic diagnostic system of the Institute.

The borescopes of stiff lense system of various lengths make it possible to do observations within side sectors and head sector in a wide range of angles of view. The borescopes are very comfortable in use during visual inspection of eges of guide vanes and rotor blades. In order to overhaul all rotor blades the inspection should be connected with simultaneous turnining the rotor by hand. Endoscopic examinations of ship engines are performed during preventive surveys once a year 
at least, for current assessment of engine technical state, in the case when to extend the between-repair time period is necessary, as well as in the case of an increased vibration level, occurrence of metal particles in lubricating oil, jump deviations from trend curves of changes of exhaust gas temperature, excessive smoking, control of flow part washing effectiveness etc.

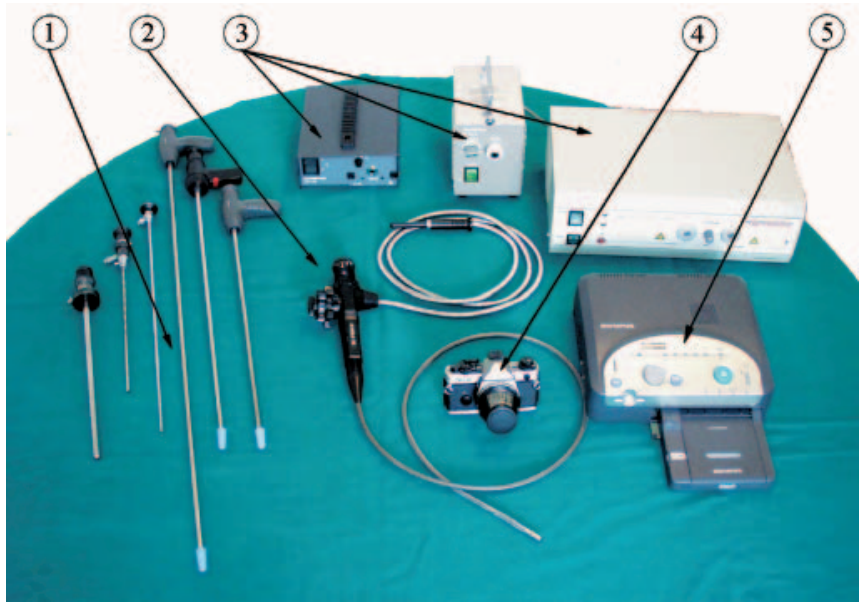

Fig. 6. The diagnostic set of OLYMPUS and STORZ firms:

1 - set of borescopes, 2 - fibrescope, 3 - set of lighting sources, 4 - digital camera, 5 - photoprinter

On the basis of multi-year endoscopic examinations of ship engines, the assessment methods of their technical state in service conditions were elaborated. They cover a necessary scope and sequence of inspections of internal spaces, which make detecting the defects in particular constructional elements of engine's flow part, possible.

For each type of the engines used on Polish Navy ships detail manuals for performing the diagnostic examinations with the use of fibrescopes and borescopes, were prepared. In Fig. 7 and 8 example places for insertion of endoscope tips into flow part of turbine engines subjected to diagnostic survey, are presented. Selected defects of ship engines, identified during endoscopic examination in operation are presented in Fig. 9; they are systematically published in scientific journals, a.o. in $[4,8,14]$.

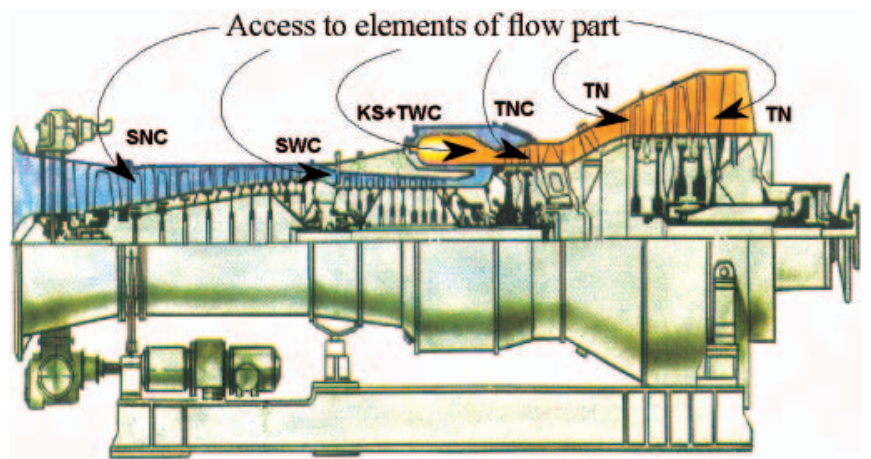

Fig. 7. Endoscopic examination of DR 76 and DR 77 gas turbine engines - access to their flow parts SNC-Low Pressure Compressor, SWC-High Pressure Compressor, KS-Combustion Chamber, TWC-High Pressure Turbine, TNC-Low Pressure Turbine, TN-Propulsion Turbine

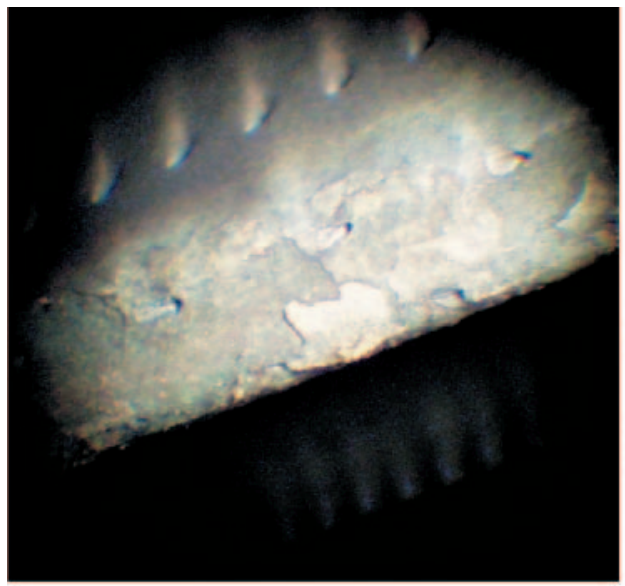

1st stage of gas generator turbine of LM-2500 engine - traces of erosion on rotor blade surface

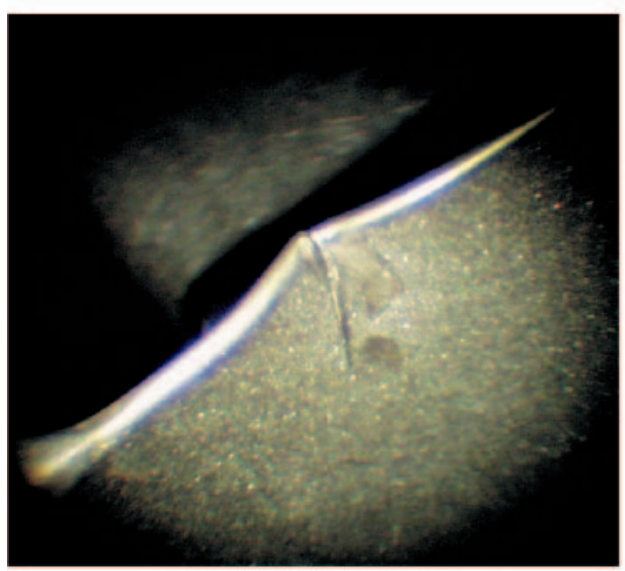

9th stage of compressor

of LM-2500 engine - dent and crack at the edge of attack of rotor blade

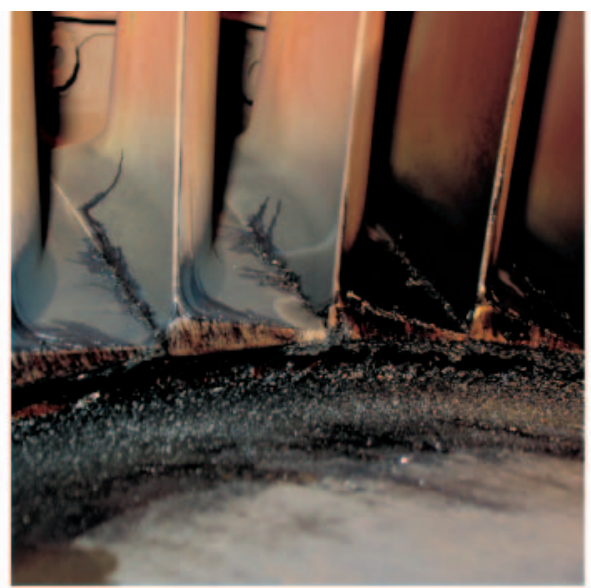

6th stage of propulsion turbine of LM-2500 engine-traces of carbon deposit on rotor blade surface

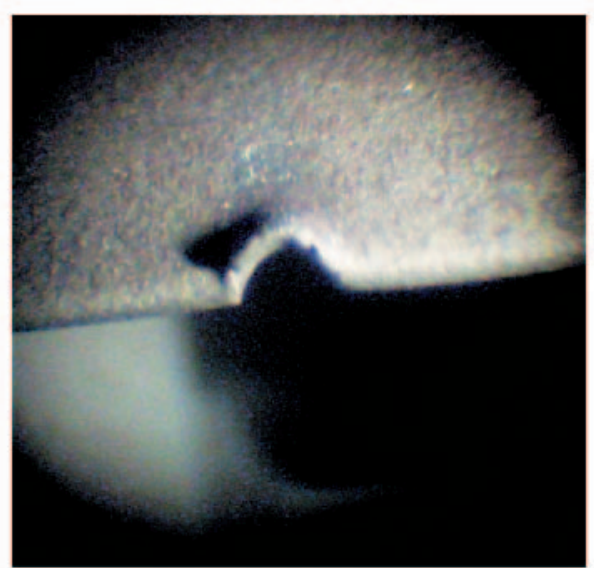

16 th stage of compressor of LM-2500 engine - dent at the edge of attack of rotor blade

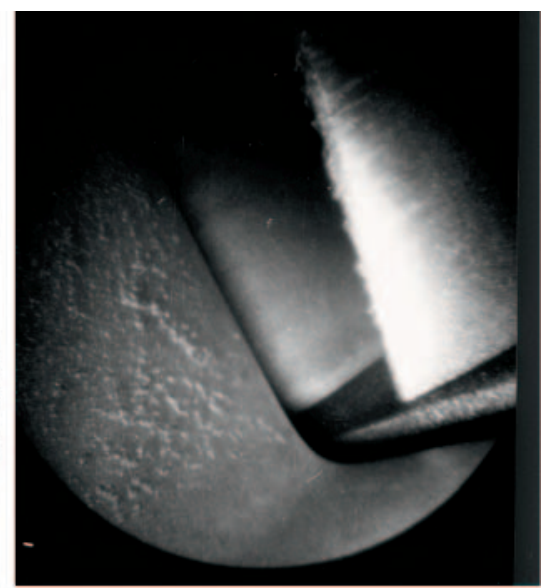

1st stage of LP compressor of DR77engine-contamination deposit on blade surfaces

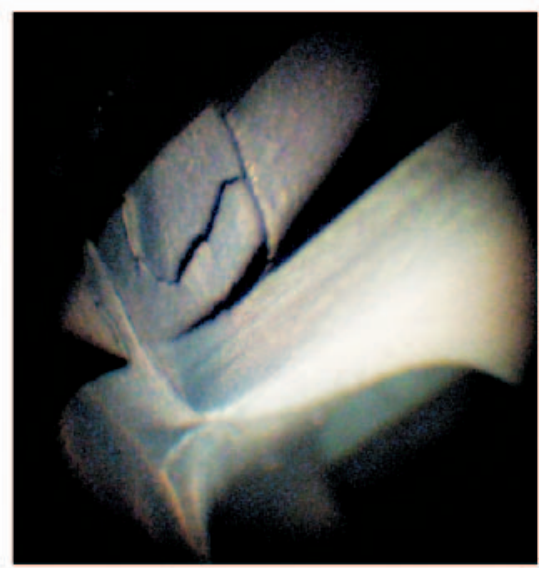

1st stage of HP turbine of DR76 engine - loss of material of blade plate

Fig. 9. Defects in ship engines identified during endoscopic examinations 


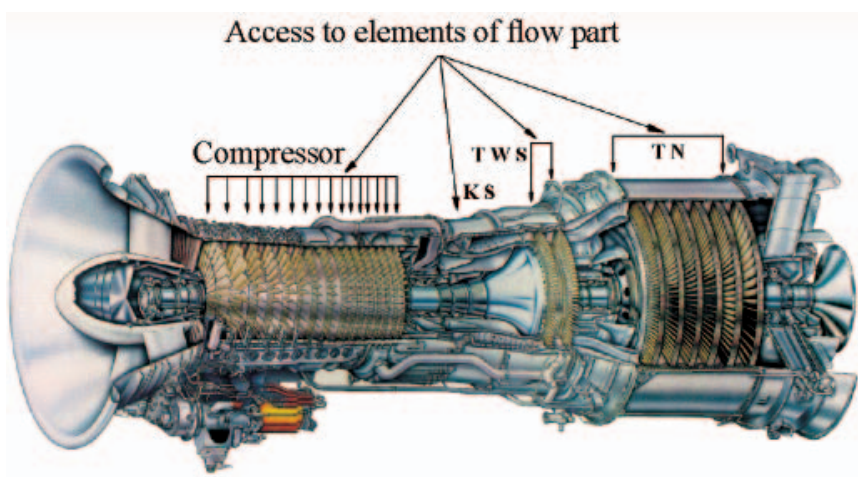

Fig. 8. Endoscopic examination of LM-2500

gas turbine engine - access to its flow part

\section{PARAMETRIC DIAGNOSTICS OF FLOW PART OF ENGINES}

From statistical data gathered by ship engine producers as well as reliability analysis based on over-twenty-year lasting service experience from operation of engines installed on board Polish Navy ships it results that this is the flow part of engines which constitutes the most troublesome functional system of turbine engine and that the dominating unserviceability state is caused by different contaminations of blade passages of compressors and turbines $[3,4,7]$. During operation process of ship engines, is systematically performed assessment of their technical state in accordance with trend analysis of changes of energy characteristics of their flow parts [12]; this is the working medium entalpy flux distribution along flow passage, $\dot{\mathrm{H}}_{\mathrm{X}-\mathrm{X}}^{*}=\mathrm{f}(\mathrm{L})$, prepared for a given load range, usually of $1.0 \mathrm{P}$, (Fig. 10).

Fig. 10. Distribution of working medium entalpy flux in characteristic

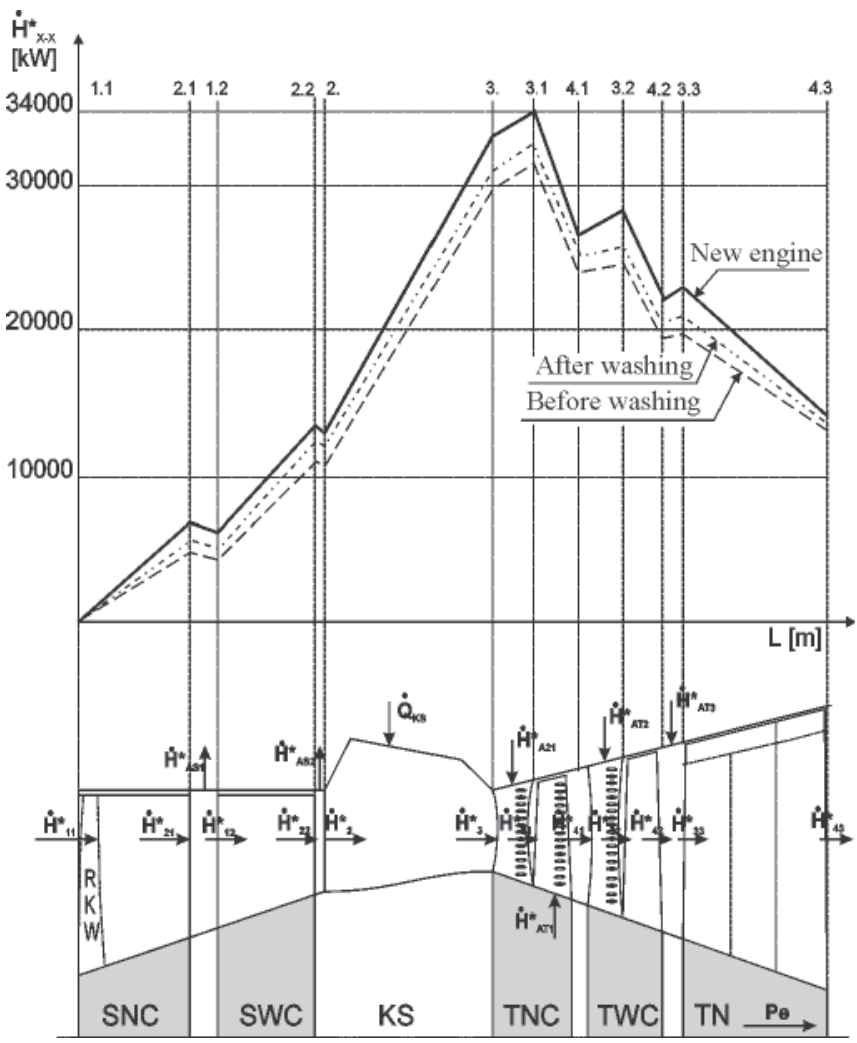

control cuts of flow part of engine [7].

The so called degree of split of energy characteristics in particular control cuts of engine flow part, $\mathrm{x}-\mathrm{x}$, determined on the basis of measurements of thermal-gas-dynamic parameters of working medium, serves as the measure of the generalized diagnostic parameter calculated by means of the following relation:

$$
\Delta \dot{\mathrm{H}}_{\mathrm{X}-\mathrm{X}}^{*}=\dot{\mathrm{H}}_{\mathrm{X}-\mathrm{X}(\mathrm{pom})}^{*}-\dot{\mathrm{H}}_{\mathrm{X}-\mathrm{X}(\mathrm{o})}^{*}
$$

Another method of assessment of technical state of engine flow part consists in analysing its dynamic features. As a result of degradation of technical state of blade passages of compressors and turbines, inertia features of unsteady thermal and flow processes in engine are changed - and in consequence - also character of gas-dynamic interaction of its rotor units. The performed tests prove that a crucial diagnostic problem is the experimental determination of changeable capability of engine to cumulating and dispersing energy and substances in its mechanical and flow systems [13]. The so far performed efforts of the Institute's research team on the problem in question resulted in the monograph devoted to diagnostic use of acceleration and deceleration processes of multi-shaft engines, as well as in promotion of two doctors specialized in diagnostic investigations of starting-up processes of ship engines, namely: Dr Włoch, J.and Dr Pojawa, B. [13, 19, 22].

In present, in the Institute are under way research projects aimed at elaboration of a method for analytical determination of energy characteristics of engine flow passage, represented in the spatial coordinate frame of time and pivot angle of guide vanes of some first stages of compressor, considered to be the independent variables of occurring unsteady processes: $\mathrm{H}_{\mathrm{X}-\mathrm{X}}^{*}=\mathrm{f}(\mathrm{L}, \tau, \alpha)$.

The so arranged characteristics are used for assessment of changes of engine dynamic features for diagnostic purposes. In this case, an important difficulty is to measure a necessary number of control parameters with no delay and with required accuracy, as well as the necessity to model characteristics of the compressor of variable flow geometry, e.g. by using controlled guide vanes of its first stages - Fig. 11 .

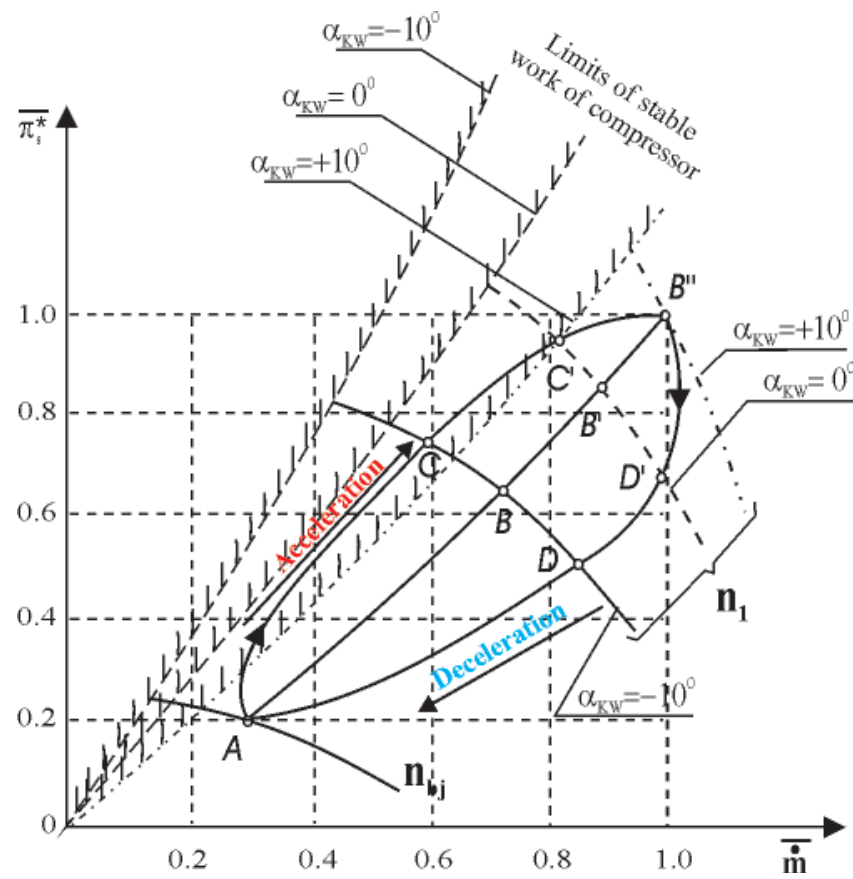

Fig 11. Change of range of operation observed in compressor characteristics, caused by interaction of controlled guide vane; $A B B$ ' $B$ "'-points of cooperation of the compressor with the network in steady states; $A C C^{\prime} B$ "- points of cooperation of the compressor with the network during engine's acceleration; $B$ ' $D$ ' $D A$ - points of cooperation of the compressor with the network during engine's deceleration.

Measurement and recording process of thermal-gasdynamic parameters is carried out with the use of special analyzers designed and built in the Institute [23]. 
The problem of model investigations of energy processes occurring in axial compressors of turbine engines of variable geometry of flow passages, has been considered in the doctor thesis of M.Sc. Wirkowski, P. [23]. Complex metrological aspects associated first of all with necessity of mounting many gauges for measuring pressure and temperature of flowing medium, seriously limit possible applications of the method to operation process of engine on board a ship. In the engines subjected to the diagnostic survey, accessible places for fitting additional measuring gauges of low inertia are very limited in number. For this reason further work on the problem will be carried out by using laboratory stand for testing GTD350 aircraft engine. The results have been achieved so far encourage to carry out experimental research in the area of influence of regulation of the fuel supply and starting-up systems of the engine, as well as influence of changes in compressor's design structure (by simulation of contamination of blade passages and guide vane angle changes) on the diagnostic measures defined for engine dynamic behaviour.

\section{RESEARCH ON VIBRATIONS}

Turbine engine vibrations result from loss of stability of its mechanical system, which means that resonance of global character appears, i.e. the whole engine vibrates, - in this case it is a designer's problem, or that of local character when one of the fundamental vibration frequencies of engine subsystem, $\mathrm{f}_{0}$, approches the frequencies of periodically changeable forces exciting vibrations, $\mathrm{f}_{\text {wym }}$.

The loss of stability of the mechanical system results from the following unfavourable phenomena which can occur and develop in the engine: the slow worsening of unbalance state of rotor systems caused by sedimentation of contaminations, erosion and corrosion of blade passages, as well as bent shafts, sudden increasing of unbalance of rotor systems caused by loss of a part of a rotating element, e.g. blade, exceedance of allowable load exerted on bearings, occurrence of friction between rotors and engine casing elements in labyrinth seals, occurrence of self-excited vibrations due to pulsatory flow of working medium (resulting from non-uniform distribution of temperature and flow velocity along flow passage circumference).

The phenomenon of resonance is of a great impact on reliability and durability of engine as it results in material fatigue and consequently - cracks in its structural elements. There are two ways leading to elimination of resonance vibrations:

$\diamond$ Making constructional improvements in order to change fundamental frequency of vibrations or that of exciting forces (a change of stiffness and mass of rotating elements),

$\diamond$ Removal - from engine operation range - of that rotational speed at which the resonance occurs.

In ship engine operation the basic method to eliminate vibrations is the systematic cleansing (washing) of its flow part and adjusting of gas temperature field in the control cut behind the combustion chamber (usually - behind gas generator turbines). In Fig. 12 the example results of measurements of transverse vibrations of DR76 turbine engine are presented together with results of harmonic analysis of excitations from the side of the engine's rotors.

The research on vibration of gas turbine engines has constituted the subject of scientific considerations of Dr. Grządziela, A., who has extended range of his interest onto vibrations generated by any arbitrary structural node of ship propulsion system of any arbitrary configuration including also the systems driven by piston combustion engines. The passive experimental research on the problem, which has been continuously carried out since 1997, is aimed at permanent improving the methods of diagnostic use of acoustic vibrational signal for assessment of state of co-axiality of engines and remaining elements of ship propulsion system and power consumer [5].

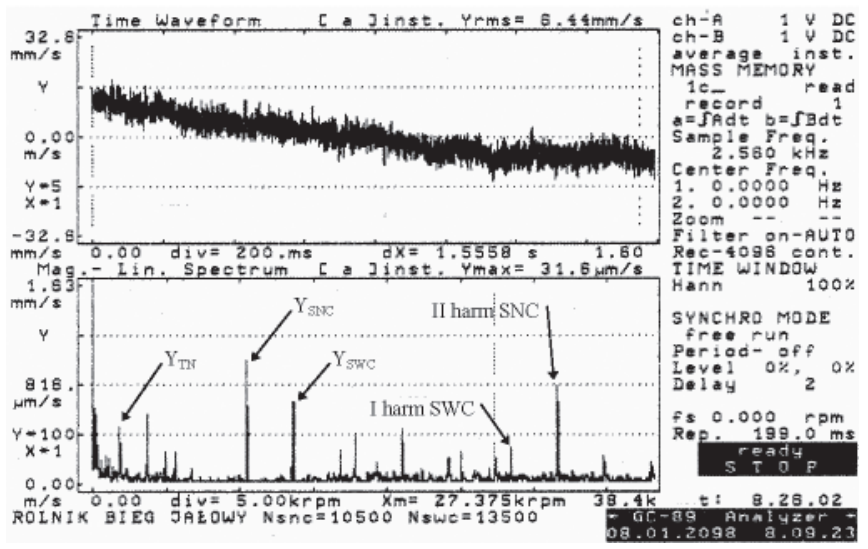

Fig. 12. Linear run and harmonic analysis of vibration signal [23]

\section{RESEARCH ON BEARING SYSTEMS}

Lubrication conditions of bearing units of gas turbine engine decide on its reliability and durability. From service experience of aircraft engines it results that most serious catastrophes of aircrafts are caused by primary, not detected in a proper time, defects of shafts and their rolling bearings. Especially, multishaft constructions of a complex kinematic system show the greatest unreliability of the bearing system, resulting from an insufficient fatigue strength.

In heavy waves, due to detrimental action of cyclic loads (impacts and shocks), the rolling bearings of ship gas turbine engines are exposed to failures. From available literature sources it results that most of the occurred defects was always preceded by accelerated wear of the most loaded elements of friction pairs, i.e. raceways of outer and inner rings, rolling elements in the form of balls and rollers as well as distance rings and sleeves and labyrinth seals. Such situation is demonstrated by increased temperature of bearing's structural elements, elevated noisiness during operation, changes in physial and chemical features of lubricating oil, as well as occurrence of metallic particles in it [16].

Hence the lubricating oil parameters can be considered carriers of diagnostic information about technical state of oillubricated friction elements of gas turbine engine. The necessary information can be obtained from results of measurements of the following items:

- Temperature and pressure in lubricating system (lubricating oil rate of flow)

- Lubricating oil consumption

- Physical and chemical features of of lubricating oil (viscosity, flash point, acid and base numbers, water content)

- Concentration of metallic contamination in the oil.

The tests make it possible to control wear process of a given friction node and to localize - by means of quantitative and qualitative analysis - its friction-dependent elements (such as the above mentioned) during gas turbine engine service. The following means and methods of diagnostic action are used:

+ Magnetic stoppers and electronic devices sygnalling metallic filings, mounted in lubricating oil outlet piping - possible detection of large ferromagnetic particles up to $1000 \mu, m$ in size 
+ Method of radioisotope fluorescence - chemical composition of metallic contaminations (small particles up to $30 \mu \mathrm{m}$ in size) is analyzed on the basis of excitation and measurement of intensity of a characteristic X-radiation of a given sample. Leading producers of gas turbines apply specific codes to indicate the sensitive structural elements covered by thin layer of noble metals, that greatly increases engine susceptibility to control in service

+ Optical methods -optical and electronic microscopes used for qualitative assessment, providing sample enlargement of 160-times (and more)

+ Detection of water content and metallic impurities of 2,5 $-30 \mu m$ in size.

The mechanical tests on contaminations (apart from metallic also graphite ones) contained in lubricating oil of ship engines and reduction gears, have been carried out by the diagnostic team of the Institute since 1992.

The example results of the tests on $\mathrm{Fe}$ and $\mathrm{Cu}$ content in lubricating oil in function of the operation time $t$ of LM-2500 engine are presented in Fig. 13.

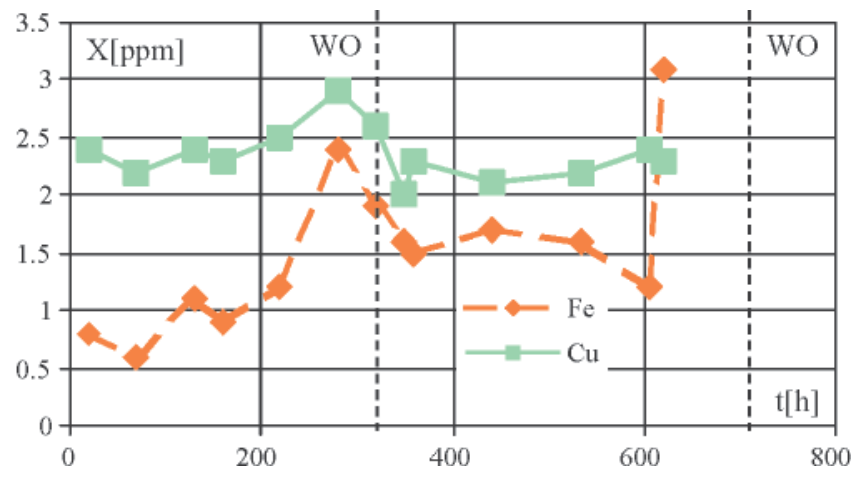

Fig. 13. Runs of changes in Fe and Cu contamination of lubricating oil in function of operation time of LM-2500 engine, WO-oil replacement [13]

On the basis of multi-year tests carried out both by the Institute and the engines' producer, as well as relevant experience of aeronautics, the limits of operational tolerance field were established: for Fe concentration $-6.0 \mathrm{ppm}$, for $\mathrm{Cu}$ concentration $-9.0 \mathrm{ppm}$. Also, trend functions which make it possible to predict friction wear intensity process in engines and reduction gears, were elaborated. With their use the scheduling of lubricating oil replacement and maintenance intervals is made. As a result of the reseach work has been carried out so far by the diagnostic team the operational manual of diagnostic tests of bearing systems for all the types of propulsion engines and reduction gears used on board Polish Navy ships, was elaborated; the achievement is based on the doctor thesis of Dr Mironiuk W. [16].

\section{RESEARCH ON FUEL OIL INJECTORS}

The basic task of fuel supply system of ship gas turbine engine is to ensure - in all possible load ranges - an adequate (qualitatively and quantitatively) fuel flux delivered to combustion chamber. Irrespective of an applied design solution, fuel oil injectors take crucial place in the system regarding reliability considerations. They ensure a high effectiveness of fuel combustion process after sufficient spraying the fuel in advance. As a result, a fuel aerosol consisted of drops of $10-20 \mu \mathrm{m}$ in diameter, is produced [1]. Such atomization of fuel makes its whole vaporization and effective combustion during flow through engine combustion chamber, possible. The greater dispersion of drops the shorter time interval necessary for vaporization and production of uniform fuel - air mixture, that determines inertance of combustion process.

In engine operation process in shipboard conditions certain disturbances can occur in correct work of particular injectors. They result from continuous process of contamination and wear of flow passages as well as deformations of characteristics of ageing control elements $[23,24]$. As a consequence, flow rate, quality of fuel atomization and geometry of its outflow from injector also become changed. Unfavourable deformations occur of gas flux temperature field behind combustion chamber, which can lead to a local overheating of its construction. Also, turbine subsystems, especially their guide vanes being under large thermal-gas-dynamic loads of pulsatory flow of working medium, are exposed to failures.

Control of technical state of injectors is necessary in order to prevent possible engine failures and the lowering of operational effectiveness of injectors. The most popular become disassembling-free control methods based on the measuring of selected parameters of thermal cycle of engine, possible to be taken in shipboard conditions. Fuel flow rate measurements, apart from the measurements of selected thermal-gas-dynamic parameters characterizing engine load, can be also a valuable source of diagnostic information on technical state of injectors [1].

In ship gas turbine engines the two-passage swirl injectors are commonly used, Fig. 14. They ensure a high effectiveness of fuel atomization over whole range of engine load changes.

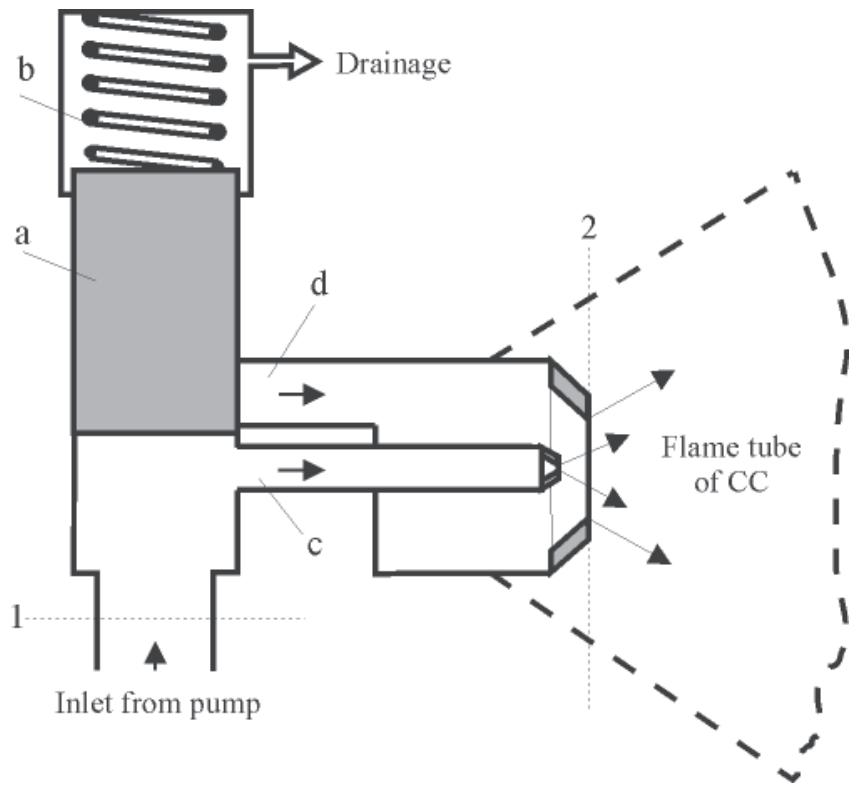

Fig. 14. Schematic diagram of fuel flow through two -passage swirl injector [1]: $\boldsymbol{a}$-fuel distributor, $\boldsymbol{b}$ - spring, $\boldsymbol{c}-1$ st passage of injector, $\boldsymbol{d}-2$ nd passage of injector, 1 and 2 - control cuts

The below given formula (2) for determination of mass flow rate of the fuel delivered to gas turbine engine injector is the most often used way of mathematical description of its work in steady states of engine operation [1]:

$$
\dot{\mathrm{m}}_{\mathrm{pal}}=\sqrt{2 \rho_{(\mathrm{T})} \Delta \mathrm{p}_{\mathrm{w}}}\left[\sum_{\mathrm{k}=1}^{\mathrm{n}}\left(\mu_{\mathrm{wyp}} \mathrm{A}_{\mathrm{wyp}}\right)_{\mathrm{k}}\right]
$$

where:

$\mathrm{k}-$ number of injectors

$\Delta \mathrm{p}=\mathrm{p}_{1}-\mathrm{p}_{2}-$ drop of pressure in injectors

$\mu_{\text {wyp }} \quad-$ fuel outflow coefficient

$\mathrm{A}_{\text {wyp }}^{\text {wyp }} \quad-$ area of spayer nozzle cross-section in fuel outflow plane. 
In the process of assessment (calculation) of rate of fuel flow into engine combustion chamber under operation, an important difficulty constitutes determination of the outflow coefficient $\mu_{\text {wyp }}$ for particular injectors. It is a function of flow character defined by Reynolds number, as well as of a form and dimensions of sprayer nozzle [23].

For this reason it is usually determined on the basis of results of experimental tests. For the analyzed type of injector the value of $\mu_{\text {wyp }}=0.92 \pm 0.02$, as determined on a laboratory stand of "cool combustion chamber", is provided by its producer [24]. The value should be considered only as a preliminary estimation. In real operation conditions of injector installed in engine, its elements are subjected to direct action of fuel combustion zone and they are heated up to high temperature (500-600K). Their flow passages become "deformed" and achieve a new, real value of the fuel outflow coefficient. Another service problem, as well as manufacturing one, is the necessity of selecting individual sets of injectors for each of the engine, to match similar values of mass flow rate for $1^{\text {st }}$ and $2^{\text {nd }}$ flow passage. Unrepeatability of their production results in a substantial scatter of flow rate values even up to $5-7 \%$ for one set of injectors [24].

The diagnostic tests of ship engine injectors are aimed at determination of an averaged value of fuel outflow coefficient for one set of injectors on the basis of measurements of gasdynamic parameters of working medium, as well as fuel combustion.

The so elaborated loading characteristics represent a relation between flow rate and mean fuel outflow coefficient in function of changes of the load determined on the basis of rotational speed of gas generator rotor coupled with fuel pump - Fig. 15.

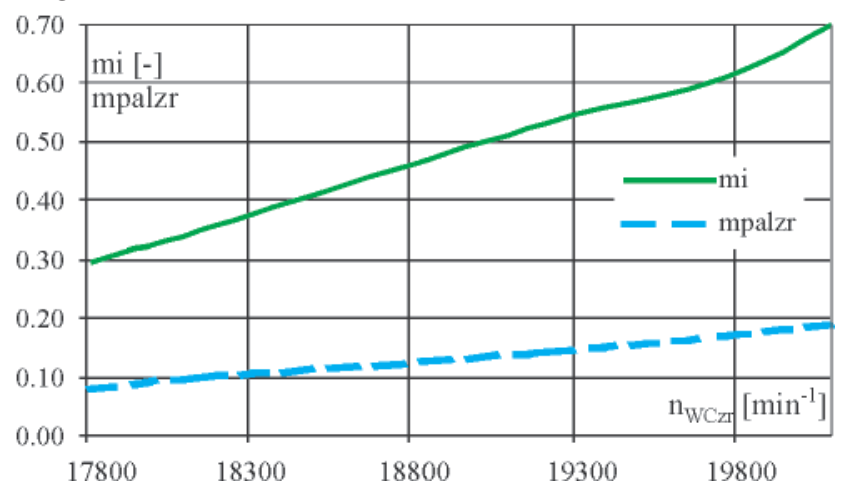

Fig. 15. Changes of mass flow rate and mean fuel outflow coefficient in function of rotational speed of rotor of HP engine DR76 [1]

Comparative analysis of the so elaborated characteristics related to the reference values recorded during the initial phase of operation makes it possible to formulate a diagnosis on technical state of flow passages of set of injectors of an engine in service.

\section{SUMMARY}

The Institute of Ship Construction and Operation, Polish Naval Academy, carries out diagnostic tests of piston and turbine engines of all kinds, installed on Polish Navy ships. On the basis of currently performed investigations it is possible to carry out operation of more than 150 engines of the total power output close to $500 \mathrm{MW}$, in accordance with their technical state.

The test stands, data base as well as diagnostic programs are successively amended and extended regarding workshop repair and changes of characteristics of engines during service.
Until now over 1000 expertises of ship propulsion systems fitted with piston and turbine combustion engines have been prepared.

Presently carried out research projects are focused on development and modernization of the basic diagnostics system to the extent which will make it possible to carry out diagnostic control of ship piston and turbine engines installed on board American-origin frigates (fitted with Detroit Diesel 16V149 TI engines and General Electric LM-2500 engines), which have been lately incorporated into Polish Navy.

\section{BIBLIOGRAPHY}

1. Białomyzy A., Korczewski Z.: „A method of experimental determination of fuel outflow coefficient for a set of injectors of ship gas turbine engine" (in Polish). 12 $2^{\text {th }}$ Symposium on Fluid Fuels and Lubricating Products used in Maritime Economy. Ministry of Transport and Maritime Economy, Szczyrk, 6-8 May 1997

2. Bruski S., Korczewski Z.: „Results of stand tests of influence of selected defects of fuel system of ship piston combustion engine on shaftline torsional vibration spectrum" (in Polish). Scientific Bulletin of Polish Naval Academy (Zeszyty Naukowe AMW), no. $2 / 2003$

3. Charchalis A.: „Diagnostics of ship gas turbine engines" (in Polish). Publishing House of Polish Naval Academy (Wydawnictwo AMW), Gdynia 1991

4. Charchalis A., Korczewski Z.: „Diagnostic methods for ship gas turbine engines" (in Polish). Mechanical Review (Przegląd Mechaniczny), no. 3,4, Warszawa 1997

5. Grządziela A.: ,A method for control of co-axiality of elements of ship propulsion systems fitted with gas turbine engines" (in Polish), Doctor thesis, Polish Naval Academy, Gdynia 1998

6. Hemingway B.E.: "A new British naval gas turbine". The Oil Engine and Gas Turbine, October, England 1959

7. Hemingway B.E.: "Surge and its implications in gas turbines", The Oil Engine and Gas Turbine, October, England 1961

8. Korczewski Z.: "Application of endoscopic methods in diagnosing the marine engines", $2^{\text {nd }}$ International Scientific Technical Conference „EXPLO-DIESEL \& GAS TURBINE'01", Gdańsk-Międzyzdroje-Kopenhaga, 23-27April 2001

9. Korczewski Z.: "An approach to modeling of gas-dynamic processes in turbo-charging system of marine four-stroke diesel engine", Polish Maritime Research no. 3/2002

10.Korczewski Z.: "Preliminary identification of gas-dynamic processes in exhaust gas channel of pulsatory supercharging system of a marine diesel engine", Polish Maritime Research no. $4 / 2002$

11.Korczewski Z.: „A method for diagnosing the ship turbocharged engines, based on results of testing gas-dynamic processes occurring in exhaust gas systems" (in Polish), Diagnostyka, Vol. 25/2003

12.Korczewski Z.: ,A method for diagnosing the flow part of gas turbine engine in service" (in Polish). Doctor thesis, Polish Naval Academy, Gdynia 1992

13.Korczewski Z.: „Identification of gas-dynamic processes in compressor unit of gas turbine engine, for diagnostic purposes" (in Polish), Assistant-professorship dissertation (a monograph), Scientific Bulletin of Polish Naval Academy (Zeszyty Naukowe AMW) no. 138A, Gdynia 1999

14.Korczewski Z., Pojawa B.: ,Endoscopic diagnostics of ship engines"(in Polish). Scientific Bulletin of Polish Naval Academy (Zeszyty Naukowe AMW), no. 3/2004

15.Kniaziewicz T., Zadrag R.: „Possibility of testing and lowering content of toxic compounds contained in exhaust gas emitted from piston combustion engines installed on board Polish Navy ships, (in Polish) 22nd Symposium on Ship Power Plants. Gdynia Maritime University, 14-15 November 2002 
16.Mironiuk W.: „Assessment of failure states of bearing systems of ship gas turbine engine" (in Polish), Doctor thesis, Polish Naval Academy, Gdynia 1995

17.Piaseczny L., Kafar I., Zadrag R., Bergier T., Kniaziewicz T.: „Report on realization of the research project no. 9T12D00613" (in Polish), Polish Naval Academy, Gdynia 1998

18.Piaseczny L., Zadrag R., Kniaziewicz T.: „A system for measuring emission of toxic compounds contained in exhaust gas from ship combustion engines" (in Polish), 23rd Symposium on Ship Power Plants, Gdynia Maritime University, Gdynia, 14-15 November 2002

19.Pojawa B.: ,, A method for diagnosing start-up system of ship gas turbine engine" (in Polish), Doctor thesis, Polish Naval Academy, Gdynia 2002

20.Polanowski S.: „A novel type of analyzer for measuring and diagnosing ship engines" (in Polish), Journal of KONES, Warszawa-Poznań 1995

21.Polanowski S. et al. „Reports on diagnostic tests of piston combustion engines operating on board Polish Navy ships" (in Polish), Research reports of Polish Naval Academy (Prace badawcze AMW), Gdynia 1992-1999
22.Włoch J.: „Diagnosing ship gas turbine engines on the basis of quantities which characterize run of starting-up and stopping operations" (in Polish), Doctor thesis, Polish Naval Academy, Gdynia 1995

23.Various authors: „,Reports on realization of $R \& D$ projects and expertises concerning diagnostics of piston and gas turbine engines operating on board Polish Navy ships" (in Polish), Research reports of Polish Naval Academy, Gdynia, 1982-2005 24. „Technical and operational documentation of the ship gas turbine engines of LM2500, DR76 and DR77 types" (in Polish).

\section{CONTACT WITH THE AUTHOR}

Zbigniew Korczewski, Ph. D.

Mechanic-Electric Faculty,

Polish Naval University Śmidowicza 69

81-103 Gdynia POLAND

e-mail: zkorczewski@wp.pl

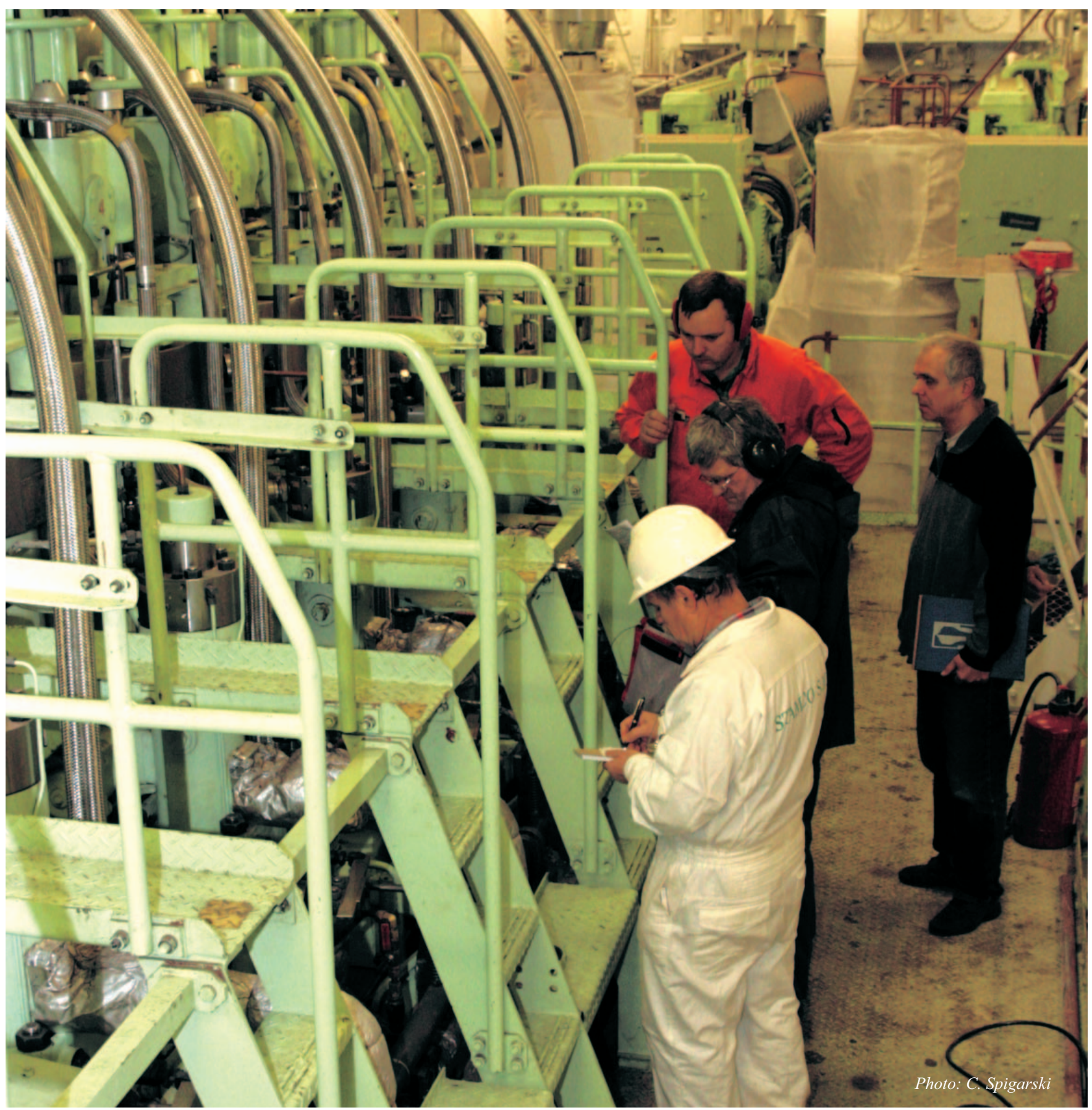

